\title{
Load shedding in power system considering the generator control and AHP algorithm
}

\author{
Tung Giang Tran ${ }^{1}$, Hoang Thi Trang ${ }^{2}$, Trong Nghia Le ${ }^{1}$, Ngoc Au Nguyen ${ }^{1}$, \\ Phu Thi Ngoc Hieu ${ }^{1}$
}

\author{
${ }^{1}$ Department of Faculty of electrical and Electronics Engineering, University of Technology and Education, Vietnam \\ ${ }^{2}$ Dong Nai Technology University, Vietnam
}

Received: 09 Oct 2020; Received in revised form: 11 Nov 2020; Accepted: 20 Nov 2020; Available online: 07 Dec 2020 (C)2020 The Author(s). Published by Infogain Publication. This is an open access article under the CC BY license (https://creativecommons.org/licenses/by/4.0/).

\begin{abstract}
This paper proposes the load shedding method with considering the ranking load importance factors. The amount of shedding power is calculated based on the Primary and Secondary adjustments to restore the system's frequency back to allowed range. The ranking and distribution shedding power on each load bus will be prosed based on the AHP algorithm. Loads with the smaller importance factor will have priority to be shed with the larger amount of shedding power and vice versa. The experimental and simulated results will be estimated on IEEE 37- bus system, the results show that the proposed method can help the frequency restores back to nominal range and reduce damages compared to the UFLS method.
\end{abstract}

Keywords - Load shedding, Primary control, Secondary control, AHP algorithm, Frequency control.

\section{INTRODUCTION}

The control of load shedding in electrical system must ensure the efficiency of both technical and economical. This helps the electrical system stables and minimizes damages in economic loss when load shedding is required.

The Under Frequency Load Shedding UFLS [1-5] and Under Voltage Load Shedding [6] method, are methods commonly used in restoring the electrical system frequency. In these methods, when the frequency or voltage fluctuates outside of the preset working limit, the frequency/voltage relays will signal to shed each respective load level, thus preventing prevent frequency/voltage attenuation and its effects. The under frequency relays are set to shed a fixed amount of load capacity in 3-5 steps when the frequency drops below the set threshold to restore the electrical system frequency. In order to increase the efficiency of load shedding, some methods of load shedding rely on frequency droop $(\mathrm{df} / \mathrm{dt})$ [7-8], or use both frequency and voltage to shed the load [9]. These methods mainly restore the frequency to permissible values and prevent blackout. To optimize the amount of load shedding, some intelligent load shedding methods are applied such as: Artificial Neural Networks (ANNs), Fuzzy Logic, Neuro fuzzy, Particle Swarm
Optimization (PSO), Genetic Algorithm (GA) [10-15]. These studies mainly focus on solving the optimization of load shedding power under the established operating mode of the power system. However, due to the complexity of the electrical system, these cases have disadvantages in the burden of computation, the speed of processing the algorithm program is relatively slow or he passive load after the frequency is below the allowed threshold, so it will take a lot of time and cause delays in the decision to shed loads leading to instability of the electricity system. In particular, in the current electricity market, ensuring the quality of electricity and reducing the economic losses of load shedding need attention.

In the load shedding problem, the selection of load hierarchy based on the shedding priority is essential for power balance adjustment and restore frequency to bring economic efficiency. Therefore, it is necessary to clearly define which loads should be listed in the list of shed load and their priority. Determination of load shedding list must satisfy many aspects which require detailed analysis consequence of load shedding. However, the calculation and analysis of these economic consequences are very complicated and in most power companies in the world today still base on the evaluation of power system experts in the world on this problem. Even so, it is difficult for 
experts to give priority to shedding these loads when considering the entire electrical system, especially when a load needs to be considered in many different aspects. However, to make it easier for experts to access, when giving their opinions, they often rely on technology characteristics and operational reality to provide verbal comments. Experts easily compare each pair and use common language such as load number 1 is more important than load number 2 , or criterion 1 is more important than criterion 2. To solve this problem, the Analytic Hierarchy Process (AHP) algorithm is used to rank loads in order of shedding priority based on consultation with experts on verbal representation.

In this paper, the minimum amount of load shedding capacity is calculated considering the primary frequency control and the secondary frequency control of the generator. The distribution of load shedding capacity at the load buses is done based on AHP algorithm. The load with the lower the importance factor will have the priority to shed more capacity and vice versa.

\section{FREQUENCY CONTROL IN POWER SYSTEM AND AHP ALGORITHM}

\subsection{The power system frequency respond}

The ability to vary power according to frequency or the frequency stability ability of a turbine is determined by the drop of the speed control characteristic [16, 17]. The drop of the adjustment characteristic is determined by the equation:

$$
R=\frac{\Delta f}{\Delta P_{G}}
$$

Where, $\mathrm{R}$ is the speed or droop adjustment factor; $\Delta f$ is the frequency change; $\Delta P_{G}$ is the change in generator power.

The relationship between power variation and frequency variation is determined by the equation:

$$
\Delta P_{\mathrm{G}}=\frac{-P_{G_{n}}}{R} \cdot \frac{\Delta f}{f_{n}}
$$

Where: $P_{G_{n}}$ is the rated power of the generators.

The load in the electricity system is a diverse collection of different electrical equipment. For resistive loads, such as lighting and heating, the power is not frequency dependent. In the case of a motor load, such as a fan and pump, the power changes with frequency causing the motor speed to change. The power of the combined load can be expressed by the following equation [18]:

$$
P_{L}=P_{I D}+P_{D}
$$

Where, $\mathrm{P}_{\mathrm{L}}$ is the combine load component, $\mathrm{P}_{\mathrm{ID}}$ is a frequency-independent load component, e.g. heat load, lighting... $\mathrm{P}_{\mathrm{D}}$ The component of the load depends on the change of frequency, e.g. motor, pump.

The response of the load to the frequency deviation is presented in the following equation:

$$
\Delta P_{L}=\Delta P_{I D}+\Delta P_{D}
$$

When the frequency is equal to the rated frequency $f_{n}$, the required power of the load is the same as the actual consumed power $\mathrm{P}_{\mathrm{L} 0}$, when the frequency decreases from $f_{n}$ to $f_{1}$, the actual power used decreases from $P_{\mathrm{L} 0}$ to $P_{\mathrm{L} 1}$.

The relationship between the load power variations with frequency variation is determined by the equation:

$$
\Delta P_{D}=-\frac{\Delta f}{f_{n}} \cdot P_{L} \cdot D
$$

Where, $\mathrm{P}_{\mathrm{L}}$ is the active power of the system's load, $\Delta \mathrm{P}_{\mathrm{D}}$ is the change of load power according to frequency change, $\mathrm{D}$ is the percentage characteristic of the change of load according to the percentage change of frequency [12], D value from $1 \%$ to $2 \%$ and experimentally determined in the power system. For example, a value of $\mathrm{D}=2 \%$ means that a $1 \%$ change in frequency will cause a $2 \%$ change in load.

2.2. Primary and secondary frequency control in power system

The process of frequency adjustment in the event of generator outage in the electrical system consists of stages: the primary frequency control, the secondary frequency control. If after adjusting the secondary frequency control, the frequency has not yet been restored to the permissible value, it is required to load shedding to restore the frequency to the permissible value.

The process of the primary and secondary frequency control was shown in Figure 1. 


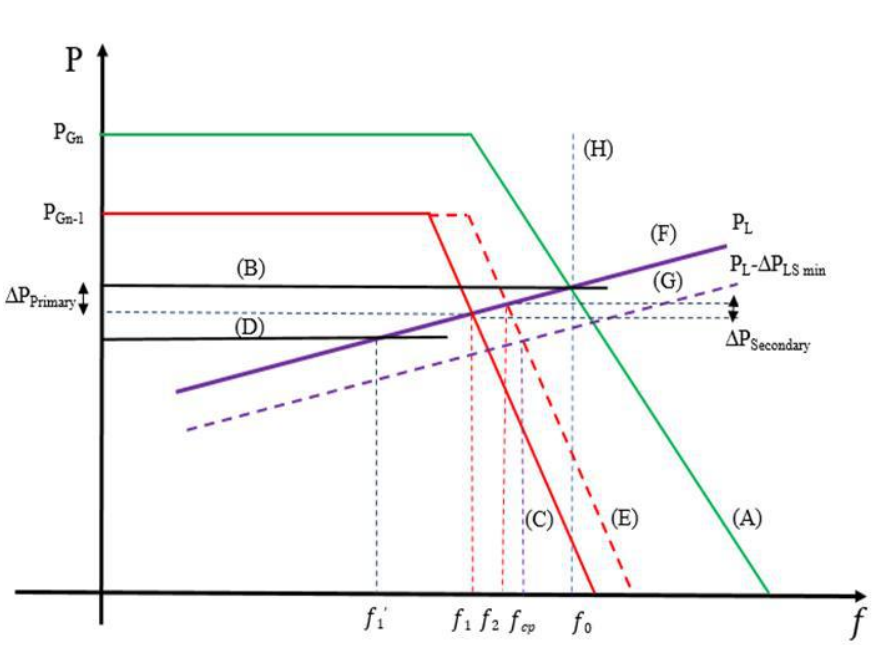

Fig. 1 The relationship between frequency deviation and output power deviation.

In the case of a generator equipped with a governor, the power characteristic is shown in the characteristic (A) of Fig 3. In stable and balanced operation mode, the point of intersection of the generator characteristic (A) with load characteristic $(F)$ determine the frequency $\mathrm{f}_{0}$. Assume that it is the standard frequency, equal to $50 \mathrm{~Hz}$ or $60 \mathrm{~Hz}$.

In case the total generator power decreases from $\mathrm{P}_{\mathrm{Gn}}$ to $\mathrm{P}_{\mathrm{Gn}-1}$, respectively, the new characteristic line $(\mathrm{C})$, the new frequency $f_{1}$ is the intersection point of the (C) characteristic with the load characteristic $(F)$.

In this case, $\mathrm{f}_{1}<\mathrm{f}_{0}$, the governor does not prevent the frequency attenuation. However, the governor has limited the large deviation of the frequency. Compared with the case where the generator does not have the governor (characteristic (D)), the intersection point with the new load characteristic $\mathrm{P}_{\mathrm{L}}$ determines the frequency $\mathrm{f}_{1}$, at this time $f_{1}{ }^{\prime}<f_{1}$.

Thus, the governor has the effect of adjusting the frequency and is called the primary frequency regulator. The effect of primary frequency adjustment depends on the slope characteristics of the generator. In the ideal case, the adjustable characteristic of the vertical generator $(\mathrm{H})$ characteristic, the frequency does not change. It is the above feature of the primary adjustment process that leads to the need for external interference (automatic control or by the operator) - that is the process of adjusting the secondary frequency.

The secondary frequency adjustment is shown by paralleling the $(\mathrm{C})$ characteristic to the $(\mathrm{E})$ characteristic of the generator, with a constant slope. The intersection point of the $(\mathrm{E})$ characteristic and the $(\mathrm{F})$ characteristic of the load determines the new frequency $f_{2}$. In case the frequency value of $f_{2}$ is smaller than the allowed value of $\mathrm{f}_{\mathrm{cp}}$, it is necessary to cut the load. The original load characteristic $(F)$ changes to the new characteristic of the load $(\mathrm{G})$. The intersection of the $(\mathrm{E})$ characteristic and the new characteristic of the load $(\mathrm{G})$ determines the allowed frequency value $\mathrm{f}_{\mathrm{cp}}$.

Thus, in the case of a power imbalance between the source and the load, the electrical system goes through stages: the primary frequency control, the secondary frequency control. After the implementation of the secondary frequency adjustment process and the electricity system frequency has not yet recovered to the permitted value, the load shedding is implemented to restore the frequency. This is seen as a last resort to avoid power system blackout and electrical system collapse.

\subsection{Minimum load - shedding calculation}

Calculating the minimum load shedding capacity $\mathrm{P}_{\mathrm{LS} \text { min }}$ ensures restoration of electricity system frequency to the allowable value, and helps to reduce the least economic damage to consumers. The calculation includes the primary control and secondary control of the generator in accordance with the actual operation.

In a power system with $\mathrm{n}$ generators, when a generator outage, the adjustment of the primary frequency of the remaining (n-1) generator is made with the adjustment of the power according to the following equation:

$$
\sum_{i=1}^{n-1} \Delta P_{\text {Primary control }}=\sum_{i=1}^{n-1} \frac{-P_{G_{n, i}}}{R_{i}} \cdot \frac{\Delta f_{1}}{f_{0}}
$$

Where, $\Delta P_{\text {Primary control }}$ is the primary control power of the i generator; $\Delta f_{1}=f_{1}-f_{0}$ is the rated power of the $\mathrm{i}$ generator; is the frequency attenuation; $f_{n}$ is the rated frequency of the power system.

When the generator outage, the difference between the generation power and the load power causes the frequency difference, in particular, to be decreased. The amount of power of the frequency-dependent load reduces the amount of $\Delta \mathrm{P}_{\mathrm{D}}$ is shown in Equation (5).

Power balance status is presented in the following equation:

$$
\begin{aligned}
& P_{L}-\Delta P_{D}=\sum_{i=1}^{n-1} P_{G_{i}}+\sum_{i=1}^{n-1} \Delta P_{\text {Primary control }} \\
& P_{L}-\sum_{i=1}^{n-1} P_{G_{i}}=\Delta P_{D}+\sum_{i=1}^{n-1} \frac{-P_{G_{\mathrm{n}, i}}}{R_{i}} \cdot \frac{\Delta f_{1}}{f_{0}}
\end{aligned}
$$




$$
\begin{aligned}
& P_{L}-\sum_{i=1}^{n-1} P_{G_{i}}=-\left(\frac{\Delta f}{f_{0}}\right) \cdot P_{L} \cdot D+\sum_{i=1}^{n-1} \frac{-P_{G_{n, i}}}{R_{i}} \cdot \frac{\Delta f_{1}}{f_{0}} \\
& P_{L}-\sum_{i=1}^{n-1} P_{G_{i}}=-\left(\frac{\Delta f_{1}}{f_{0}}\right)\left(P_{L} \cdot D+\sum_{i=1}^{n-1} \frac{P_{G_{n, i}}}{R_{i}}\right)
\end{aligned}
$$

Set $\Delta P_{L}=P_{L}-\sum_{i=1}^{n-1} P_{G_{i}}$ and $\beta=P_{L} . D+\sum_{i=1}^{n-1} \frac{P_{G_{n, i}}}{R_{i}}$

From (10) infer: $\Delta P_{L}=\frac{-\Delta f_{1}}{f_{n}} \cdot \beta$

In the case of the considering secondary control power, the new power balance equation with the new frequency value $\mathrm{f}_{2}$, the equation (7) becomes:

$$
P_{L}-\Delta P_{D}=\sum_{i=1}^{n-1} P_{G_{i}}+\sum_{i=1}^{n-1} \Delta P_{\text {Primary control }}+\Delta P_{\text {Secondary control max }}
$$

Where, $\Delta P_{\text {Secondary control max }}$ is the maximum amount of secondary control power supplied to the power system.

$$
\Delta P_{\text {Secondary control max }}=P_{G m, j}-\Delta P_{\text {Primary control, } \mathrm{j}}
$$

After performing the secondary control process but the system frequency has not yet been restored to the allowable value, then load shedding is required to restore the frequency, the minimum amount of load shedding power $\mathrm{P}_{\mathrm{LS} \text { min }}$ is calculated by the following equation:

$$
\begin{aligned}
& P_{L}-\Delta P_{D}-P_{L S \min }=\sum_{i=1}^{n-1} P_{G_{i}}+\sum_{i=1}^{n-1} \Delta P_{\text {Primary control }}+\Delta P_{\text {Secondary control max }} \\
& \Delta P_{L S \text { min }}=P_{L}-\Delta P_{D}-\sum_{i=1}^{n-1} P_{G_{i}}-\sum_{i=1}^{n-1} \Delta P_{\text {Primary control }}-\Delta P_{\text {Secondary control max }} \\
& \Delta P_{L S \text { min }}=P_{L}-\sum_{i=1}^{n-1} P_{G_{i}}+\frac{\Delta f_{c p}}{f_{0}} \cdot P_{L} \cdot D+\sum_{i=1}^{n-1} \frac{P_{G_{n, i}}}{R_{i}} \cdot \frac{\Delta f_{c p}}{f_{0}}-\Delta P_{\text {Sceondary control max }}
\end{aligned}
$$

Equation (15) is abbreviated according to the following equation:

$$
\Delta P_{L S \text { min }}=\Delta P_{L}+\frac{\Delta f_{c p}}{f_{0}} \cdot \beta-\Delta P_{\text {Secondary control max }}
$$

\subsection{Analytic Hierarchy Process (AHP)}

Analytic Hierarchy Process (AHP) [19] is one of Multi Criteria decision making method that was originally developed by Prof. Thomas L. Saaty. In short, it is a method to derive ratio scales from paired comparisons. This method presents assessment method and criteria, and works collectively to arrive at a final decision. AHP is particularly well suited for case studies involving quantitative and analytical, making decisions when there are multiple standards-dependent alternatives with multiple interactions.

The steps of the AHP algorithm can be expressed as follows:

Step 1: Set up a decision hierarchy model.

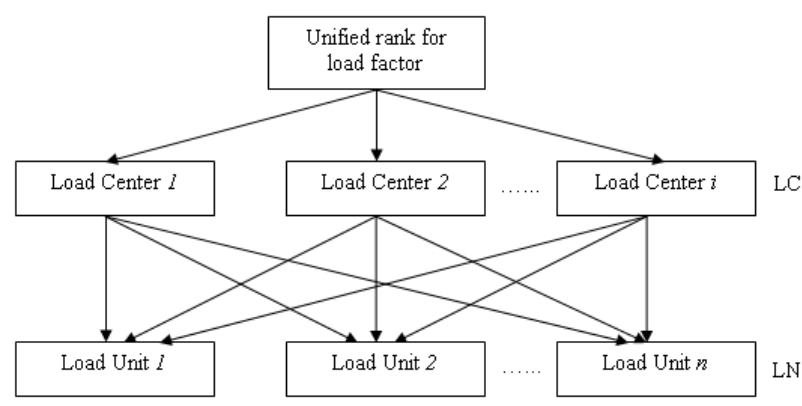

Fig. 2 AHP model of the arrangement of units

Step 2: Build judgment matrix LC and LN that show the important factor between load centers (LC) and load nodes (LN) each other of the power system. The value of elements in the judgment matrix reflects the user's knowledge about the relative importance between every pair of factors.

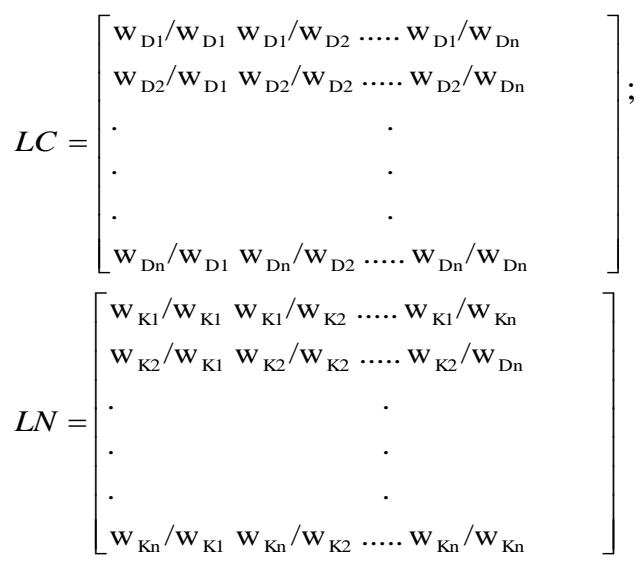

where, $\mathrm{wD}_{\mathrm{i}} / \mathrm{wD}_{\mathrm{j}}$ is the relative importance of the $\mathrm{i}^{\text {th }}$ load node compared with the $\mathrm{j}^{\text {th }}$ load node; $\mathrm{wk}_{\mathrm{i}} / \mathrm{wk}_{\mathrm{j}}$ is the relative importance of the $\mathrm{i}^{\text {th }}$ load center compared with the $\mathrm{j}^{\text {th }}$ load center. The value of $\mathrm{wk}_{\mathrm{i}} / \mathrm{wk}_{\mathrm{j}}, \mathrm{wD}_{\mathrm{i}} / \mathrm{wD}_{\mathrm{j}}$ can be obtained according to the experience of electrical engineers or system operators by using some " $1-9$ " ratio scale methods. According to the principle of AHP, the weighting factors of the loads can be determined through the ranking computation of a judgment matrix, which reflects the judgment and comparison of a series of pair of factors. Therefore, the unified weighting factor of the load nodes of the power system can be obtained from the following equation:

$$
\mathrm{W}_{\mathrm{ij}}=\mathrm{W}_{\mathrm{Kj}} \mathrm{x} \mathrm{W}_{\mathrm{Di}} \quad \mathrm{Di} \in \mathrm{K}_{\mathrm{j}}
$$


where, $\mathrm{Di} \in \mathrm{Kj}$ means load node $\mathrm{D}_{\mathrm{i}}$ is located in load center $\mathrm{K}_{\mathrm{j}}$.

Step 3: Calculate the load importance factor of center regions together and the load importance factors of each load unit in the same load area on the basis of constructing judgment matrix. According to the principle of AHP algorithm, the load importance factors can be calculated through the calculation of the maximum eigenvalue and the eigenvector of the judgment matrix.

To calculate the eigenvalue of matrix largest judgment, can use the root methods.

- Multiply all the components in each row of the judgment matrix.

$$
M_{i}=\prod_{i} X_{i j}, \mathrm{i}=1, \ldots, \mathrm{n} ; \mathrm{j}=1, \ldots, \mathrm{n}
$$

Here, $\mathrm{n}$ is the dimension of the judgment matrix $\mathrm{A}, \mathrm{X}_{\mathrm{ij}}$ is the element of the matrix A.

- Calculate the $\mathrm{n}^{\text {th }}$ root of $\mathrm{M}_{\mathrm{i}}$

$W_{i}^{*}=\sqrt[n]{M_{i}} \quad \mathrm{i}=1, \ldots, \mathrm{n}$

Vector $\mathrm{W} *: W^{*}=\left[W_{1}^{*}, W_{2}^{*}, \ldots, W_{n}^{*}\right]^{T}$

- $\quad$ Standardize vector $\mathrm{W}^{*}$

$$
W_{i}=\frac{W_{i}^{*}}{\sum_{j=1}^{n} W_{j}^{*}}, \mathrm{i}=1, \ldots, \mathrm{n}
$$

In this way, there are eigenvectors of matrix A,

$$
W=\left[W_{1}, W_{2}, \ldots, W_{n}\right]^{T}
$$

Step 4: Hierarchy ranking and check the consistency of the results. Sort in descending order of the load importance factor of each load unit to implement a load shedding strategy according to priority level.

\subsection{The proposed method}

When there is a generator failure in the electrical system, the frequency will be reduced. Systems that control the Primary and the Secondary adjustments will be implemented to restore the frequency. In case the frequency is still not restored to permissible range, load shedding must be processed to restore frequency to permissible value. The AHP algorithm is applied to calculate the load importance factor of and rank these loads. The distributed shedding power at each load buses is based on this factor. Loads with the smaller importance factor will have priority to be shed with the larger amount of shedding power and vice versa. Flowchart of the load shedding process based on AHP algorithm is shown in Figure 3.

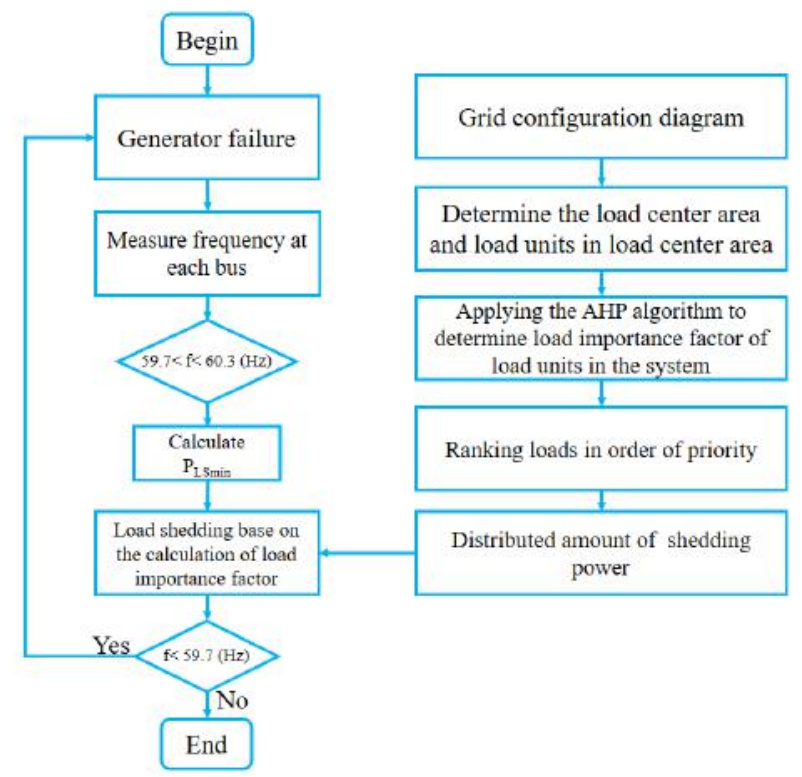

Fig.3 The flow chart of load shedding base on the AHP algorithm

\section{CASE STUDIES}

The proposed method is tested on the IEEE 37-bus 9generators electrical system [20]. The single line diagram of the system is shown in Figure 5. The generator at Bus31 is considered the Slack Bus.

From the single diagram of the electrical system, build a model of the hierarchy between the load centers and the loads in the load center. The results of building the model hierarchy are presented in Figure 4.

Next, construct judgment matrices that show the importance of the load centers to each other and the importance of the loads in the load center. Construction results are presented from Table 1 to Table 5 .

Table 1. The judgment matrix of load center $L C_{i}$

\begin{tabular}{|c|c|c|c|c|}
\hline $\mathbf{P I}$ & $\mathbf{L C}_{\mathbf{1}}$ & $\mathbf{L C}_{\mathbf{2}}$ & $\mathbf{L C}_{\mathbf{3}}$ & $\mathbf{L C}_{\mathbf{4}}$ \\
\hline $\mathrm{LC}_{1}$ & $1 / 1$ & $1 / 3$ & $1 / 1$ & $1 / 1$ \\
\hline $\mathrm{LC}_{2}$ & $3 / 1$ & $1 / 1$ & $1 / 1$ & $3 / 1$ \\
\hline $\mathrm{LC}_{3}$ & $1 / 1$ & $1 / 1$ & $1 / 1$ & $1 / 2$ \\
\hline $\mathrm{LC}_{4}$ & $1 / 1$ & $1 / 3$ & $2 / 1$ & $1 / 1$ \\
\hline
\end{tabular}


Table 5. The judgment matrix of load $L_{j}$ at $L C_{4}$

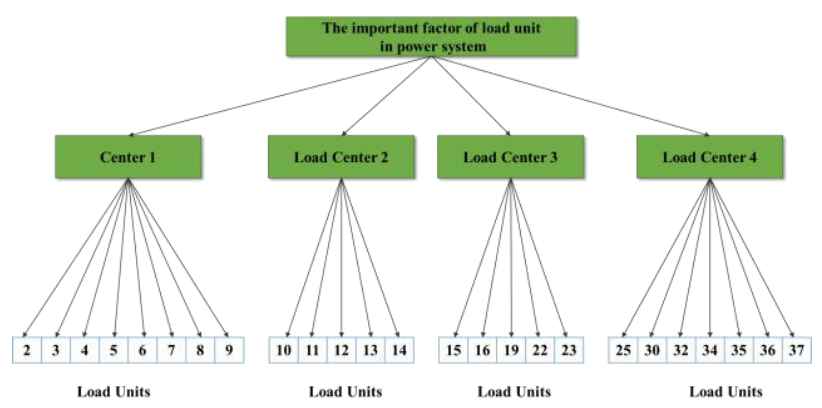

Fig. 4 AHP model for load centers and load units in IEEE 37 bus 9 generator

Table 2. The judgment matrix of load $L_{j}$ at $L C_{l}$

\begin{tabular}{|l|c|c|c|c|c|c|c|c|}
\hline & $\mathbf{L}_{2}$ & $\mathbf{L}_{3}$ & $\mathbf{L} 4$ & $\mathbf{L} 5$ & $\mathbf{L} 6$ & $\mathbf{L} 7$ & $\mathbf{L} 8$ & $\mathbf{L} 9$ \\
\hline $\mathbf{L}_{2}$ & $1 / 1$ & $1 / 1$ & $1 / 1$ & $1 / 3$ & $1 / 2$ & $1 / 3$ & $1 / 2$ & $1 / 2$ \\
\hline $\mathbf{L}_{3}$ & $1 / 1$ & $1 / 1$ & $3 / 1$ & $1 / 1$ & $2 / 1$ & $1 / 1$ & $2 / 1$ & $1 / 1$ \\
\hline $\mathbf{L}_{4}$ & $1 / 1$ & $1 / 3$ & $1 / 1$ & $1 / 2$ & $1 / 1$ & $1 / 2$ & $1 / 1$ & $2 / 1$ \\
\hline $\mathbf{L}_{5}$ & $3 / 1$ & $1 / 1$ & $2 / 1$ & $1 / 1$ & $1 / 3$ & $1 / 3$ & $1 / 1$ & $1 / 3$ \\
\hline $\mathbf{L}_{6}$ & $2 / 1$ & $1 / 2$ & $1 / 1$ & $3 / 1$ & $1 / 1$ & $1 / 1$ & $3 / 1$ & $1 / 3$ \\
\hline $\mathbf{L}_{7}$ & $3 / 1$ & $1 / 1$ & $2 / 1$ & $3 / 1$ & $1 / 1$ & $1 / 1$ & $1 / 2$ & $1 / 1$ \\
\hline $\mathbf{L}_{8}$ & $2 / 1$ & $1 / 2$ & $1 / 1$ & $1 / 1$ & $1 / 3$ & $2 / 1$ & $1 / 1$ & $1 / 2$ \\
\hline $\mathbf{L}_{9}$ & $2 / 1$ & $1 / 1$ & $1 / 2$ & $3 / 1$ & $3 / 1$ & $1 / 1$ & $2 / 1$ & $1 / 1$ \\
\hline
\end{tabular}

Table 3. The judgment matrix of load $L_{j}$ at $L C_{2}$

\begin{tabular}{|l|c|c|c|c|c|}
\hline & $\mathbf{L}_{10}$ & $\mathbf{L}_{11}$ & $\mathbf{L}_{12}$ & $\mathbf{L}_{13}$ & $\mathbf{L}_{14}$ \\
\hline $\mathbf{L}_{10}$ & $1 / 1$ & $1 / 1$ & $1 / 1$ & $1 / 3$ & $1 / 2$ \\
\hline $\mathbf{L}_{11}$ & $1 / 1$ & $1 / 1$ & $3 / 1$ & $1 / 1$ & $1 / 1$ \\
\hline $\mathbf{L}_{12}$ & $1 / 1$ & $1 / 3$ & $1 / 1$ & $1 / 2$ & $2 / 1$ \\
\hline $\mathbf{L}_{13}$ & $3 / 1$ & $1 / 1$ & $2 / 1$ & $1 / 1$ & $1 / 3$ \\
\hline $\mathbf{L}_{14}$ & $2 / 1$ & $1 / 1$ & $1 / 2$ & $3 / 1$ & $1 / 1$ \\
\hline
\end{tabular}

Table 4. The judgment matrix of load $L_{j}$ at $L C_{3}$

\begin{tabular}{|l|c|c|c|c|c|}
\hline & $\mathbf{L}_{15}$ & $\mathbf{L}_{16}$ & $\mathbf{L}_{19}$ & $\mathbf{L}_{22}$ & $\mathbf{L}_{23}$ \\
\hline $\mathbf{L}_{15}$ & $1 / 1$ & $1 / 2$ & $1 / 1$ & $1 / 1$ & $1 / 2$ \\
\hline $\mathbf{L}_{16}$ & $2 / 1$ & $1 / 1$ & $3 / 1$ & $1 / 3$ & $1 / 1$ \\
\hline $\mathbf{L}_{19}$ & $1 / 1$ & $1 / 3$ & $1 / 1$ & $1 / 2$ & $2 / 1$ \\
\hline $\mathbf{L}_{22}$ & $1 / 1$ & $3 / 1$ & $2 / 1$ & $1 / 1$ & $1 / 3$ \\
\hline $\mathbf{L}_{23}$ & $2 / 1$ & $1 / 1$ & $1 / 2$ & $3 / 1$ & $1 / 1$ \\
\hline
\end{tabular}

\begin{tabular}{|l|c|c|c|c|c|c|c|}
\hline & $\mathbf{L} 25$ & $\mathbf{L} 30$ & $\mathbf{L} 32$ & $\mathbf{L} 34$ & $\mathbf{L} 35$ & $\mathbf{L} 36$ & $\mathbf{L} 37$ \\
\hline $\mathbf{L}_{25}$ & $1 / 1$ & $1 / 1$ & $1 / 1$ & $1 / 3$ & $1 / 2$ & $1 / 3$ & $1 / 2$ \\
\hline $\mathbf{L} 30$ & $1 / 1$ & $1 / 1$ & $3 / 1$ & $1 / 1$ & $1 / 1$ & $1 / 1$ & $1 / 1$ \\
\hline $\mathbf{L} 32$ & $1 / 1$ & $1 / 3$ & $1 / 1$ & $1 / 2$ & $2 / 1$ & $1 / 2$ & $2 / 1$ \\
\hline $\mathbf{L} 34$ & $3 / 1$ & $1 / 1$ & $2 / 1$ & $1 / 1$ & $1 / 3$ & $1 / 3$ & $1 / 1$ \\
\hline $\mathbf{L} 35$ & $2 / 1$ & $1 / 1$ & $1 / 2$ & $3 / 1$ & $1 / 1$ & $1 / 1$ & $3 / 1$ \\
\hline $\mathbf{L} 36$ & $3 / 1$ & $1 / 1$ & $2 / 1$ & $3 / 1$ & $1 / 1$ & $1 / 1$ & $1 / 2$ \\
\hline $\mathbf{L} 37$ & $2 / 1$ & $1 / 1$ & $1 / 2$ & $1 / 1$ & $1 / 3$ & $2 / 1$ & $1 / 1$ \\
\hline
\end{tabular}

From the values of judgment matrix, apply AHP algorithm presented in 2.4 section to calculate the importance factor of the load. Parameter values of the load and the results of calculation of the importance factor of the load are presented in Table 6:

Table 6. The values of the loads and the importance factor of the load are calculated by AHP

\begin{tabular}{|c|c|c|c|c|c|c|}
\hline $\begin{array}{c}\text { Load } \\
\text { cente } \\
\mathbf{r}\end{array}$ & $\begin{array}{c}\mathbf{W}_{\mathbf{L C i}} \\
\mathbf{W}_{\mathbf{k j}}\end{array}$ & $\begin{array}{l}\text { Load } \\
\text { Bus t }\end{array}$ & $\begin{array}{c}\text { Cost } \\
\mathbf{C}_{\mathbf{m i}}(\$ / \\
\mathbf{k W})\end{array}$ & $\begin{array}{c}\mathbf{W}_{\mathrm{Lj}} \\
\text { (load } \\
\text { unit) }\end{array}$ & $\begin{array}{c}\text { The } \\
\text { impor } \\
\text { t tanct } \\
\text { factor } \\
W_{i j}\end{array}$ & $\begin{array}{c}\mathbf{P}_{\text {LSi }} \\
(\mathbf{M} \\
\mathbf{W})\end{array}$ \\
\hline $\mathrm{LC} 1$ & 0.18 & $\mathrm{~L}_{2}$ & 220 & 0.07 & 0.0126 & 1.68 \\
\hline LC1 & 0.18 & $\mathrm{~L}_{3}$ & 200 & 0.16 & 0.0293 & 0.72 \\
\hline $\mathrm{LC} 1$ & 0.18 & $\mathrm{~L}_{4}$ & 280 & 0.10 & 0.0172 & 1.23 \\
\hline LC1 & 0.18 & $\mathrm{~L}_{5}$ & 200 & 0.10 & 0.0178 & 1.19 \\
\hline LC1 & 0.18 & $\mathrm{~L}_{6}$ & 250 & 0.14 & 0.0246 & 0.86 \\
\hline LC1 & 0.18 & $\mathrm{~L}_{7}$ & 300 & 0.16 & 0.0283 & 0.75 \\
\hline LC1 & 0.18 & $\mathrm{~L}_{8}$ & 280 & 0.10 & 0.0187 & 1.13 \\
\hline $\mathrm{LC} 1$ & 0.18 & $\mathrm{~L}_{9}$ & 280 & 0.17 & 0.0308 & 0.69 \\
\hline $\mathrm{LC} 2$ & 0.41 & $\mathrm{~L}_{10}$ & 245 & 0.07 & 0.0556 & 0.38 \\
\hline $\mathrm{LC} 2$ & 0.41 & $\mathrm{~L}_{11}$ & 280 & 0.14 & 0.0991 & 0.21 \\
\hline $\mathrm{LC} 2$ & 0.41 & $\mathrm{~L}_{12}$ & 220 & 0.24 & 0.0638 & 0.33 \\
\hline $\mathrm{LC} 2$ & 0.41 & $\mathrm{~L}_{13}$ & 280 & 0.16 & 0.0913 & 0.23 \\
\hline $\mathrm{LC} 2$ & 0.41 & $\mathrm{~L}_{14}$ & 220 & 0.22 & 0.0991 & 0.21 \\
\hline LC3 & 0.20 & $\mathrm{~L}_{15}$ & 280 & 0.15 & 0.0295 & 0.72 \\
\hline LC3 & 0.20 & $\mathrm{~L}_{16}$ & 220 & 0.23 & 0.0447 & 0.47 \\
\hline LC3 & 0.20 & $\mathrm{~L}_{19}$ & 245 & 0.16 & 0.0312 & 0.68 \\
\hline LC3 & 0.20 & $\mathrm{~L}_{22}$ & 220 & 0.23 & 0.0447 & 0.47 \\
\hline LC3 & 0.20 & $\mathrm{~L}_{23}$ & 280 & 0.24 & 0.0484 & 0.44 \\
\hline
\end{tabular}




\begin{tabular}{|l|l|l|l|l|l|l|}
\hline LC4 & 0.21 & $\mathrm{~L}_{25}$ & 280 & 0.08 & 0.0176 & 1.2 \\
\hline LC4 & 0.21 & $\mathrm{~L}_{30}$ & 220 & 0.16 & 0.0344 & 0.62 \\
\hline LC4 & 0.21 & $\mathrm{~L}_{32}$ & 250 & 0.12 & 0.0252 & 0.84 \\
\hline LC4 & 0.21 & $\mathrm{~L}_{34}$ & 300 & 0.13 & 0.0278 & 0.76 \\
\hline LC4 & 0.21 & $\mathrm{~L}_{35}$ & 245 & 0.19 & 0.0403 & 0.53 \\
\hline LC4 & 0.21 & $\mathrm{~L}_{36}$ & 280 & 0.19 & 0.0403 & 0.53 \\
\hline LC4 & 0.21 & $\mathrm{~L}_{37}$ & 300 & 0.13 & 0.0278 & 0.76 \\
\hline
\end{tabular}

Table 7. Value of parameters and primary control power of the generators

To test the effectiveness of the proposed method, the situations of deactivation or disconnection of the electricity system of these generators are calculated, simulated and tested parameters such as: frequency, the amount of primary control power, the amount of secondary control power, and minimal load shedding power. In cases of calculation and simulation, the power for controlling primary and secondary frequencies is implemented. All test cases were simulated on PowerWorld GSO 19 software.

In the case study, the generator JO345 \# 1 (bus 28) is disconnected from the grid. Applying the equation (11) calculate the stable frequency value when the generator JO345 \# 1 (bus 28) outage is $59.6 \mathrm{~Hz}$.

Therefore, it is necessary to implement the process of primary frequency control and secondary frequency control to restore frequency. The adjustment of primary frequency is done automatically. The reaction of the turbine governor is performed immediately after the generator JO345 \# 1 (bus 28) is disconnected. The primary control power values of each generator turbine are shown in Table 7.

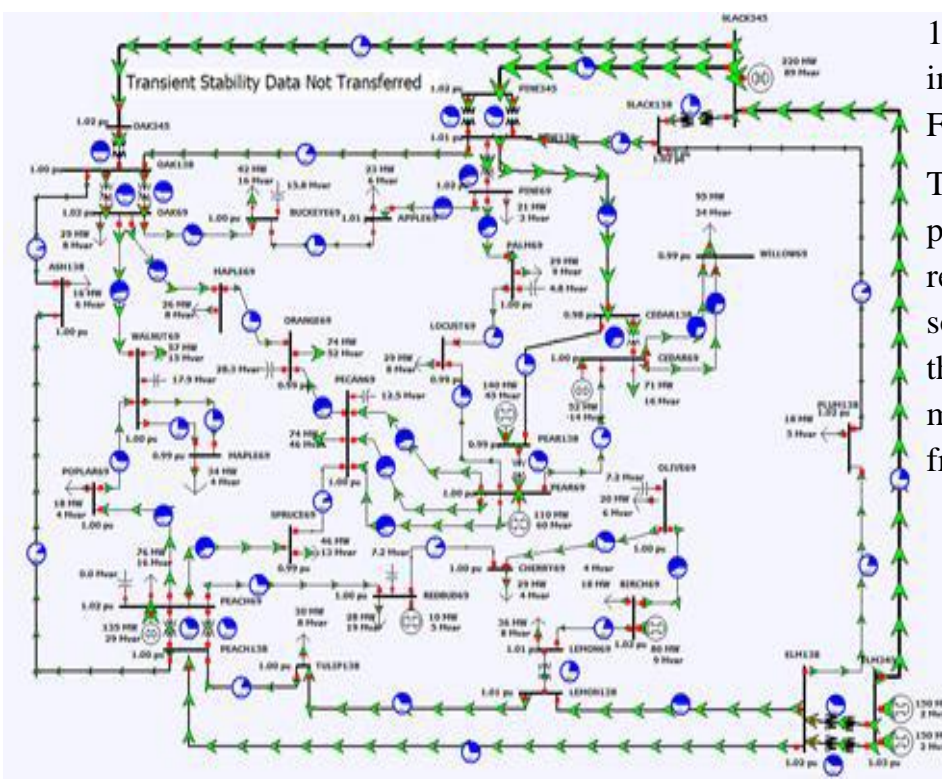

\begin{tabular}{|c|c|c|c|c|c|c|}
\hline No & Gen & $\mathbf{P}_{\mathbf{G}(\mathrm{MW})}$ & $\mathbf{P}_{\mathbf{G}(\mathbf{p u})}$ & $\mathbf{R}$ & $\Delta P_{\mathrm{Pri}}$ & $\frac{P_{G, n}}{R}$ \\
\hline 1 & \begin{tabular}{|l|} 
WEBER \\
69
\end{tabular} & 31.5 & 0.315 & 0.05 & $\begin{array}{c}0.03 \\
5\end{array}$ & 7 \\
\hline 2 & \begin{tabular}{|l|} 
JO345\# \\
1
\end{tabular} & 0 & 0 & 0.05 & 0 & 0 \\
\hline 3 & \begin{tabular}{|l|} 
JO345\# \\
2
\end{tabular} & 135 & 1.35 & 0.05 & 0.15 & 30 \\
\hline 4 & \begin{tabular}{|l|} 
SLACK \\
345
\end{tabular} & 187.28 & 1.8728 & 0.05 & 0.22 & 44 \\
\hline 5 & \begin{tabular}{|l|} 
LAUF6 \\
9
\end{tabular} & 135 & 1.35 & 0.05 & 0.15 & 30 \\
\hline 6 & BOB69 & 46 & 0.46 & 0.05 & $\begin{array}{c}0.05 \\
2\end{array}$ & 10.4 \\
\hline 7 & $\begin{array}{l}\text { ROGER } \\
69\end{array}$ & 72 & 0.72 & 0.05 & 0.08 & 16 \\
\hline 8 & \begin{tabular}{|l|} 
BLT138 \\
\end{tabular} & 126 & 1.26 & 0.05 & 0.14 & 28 \\
\hline 9 & BLT69 & 99 & 0.99 & 0.05 & 0.11 & 22 \\
\hline & Total & 831.78 & 8.3178 & & $\begin{array}{c}0.93 \\
7\end{array}$ & $\begin{array}{l}187 . \\
4\end{array}$ \\
\hline
\end{tabular}

Because the recovery frequency is less than the allowed value, the secondary frequency control process is performed after the primary control. In the IEEE 37 bus 9generator electrical system diagram, the SLACK 345 (SLACK Bus) is selected as the secondary frequency control generator. In this case, application equation (13) calculates the amount of the secondary control power of 10.72MW. The frequency of the system after the implementation of the secondary control is shown in Figure 6.

Thus, after performing the secondary frequency control process, the recovery frequency is $59.66 \mathrm{~Hz}$ and has not returned to the allowed value. Therefore, the ultimate solution cuts or reduces the load to restore the frequency to the allowable value. Applying Equation (17) calculates the minimum amount of power load shedding to restore the frequency to the allowable value.

Fig. 5: The IEEE 37 bus 9 generators test system. 


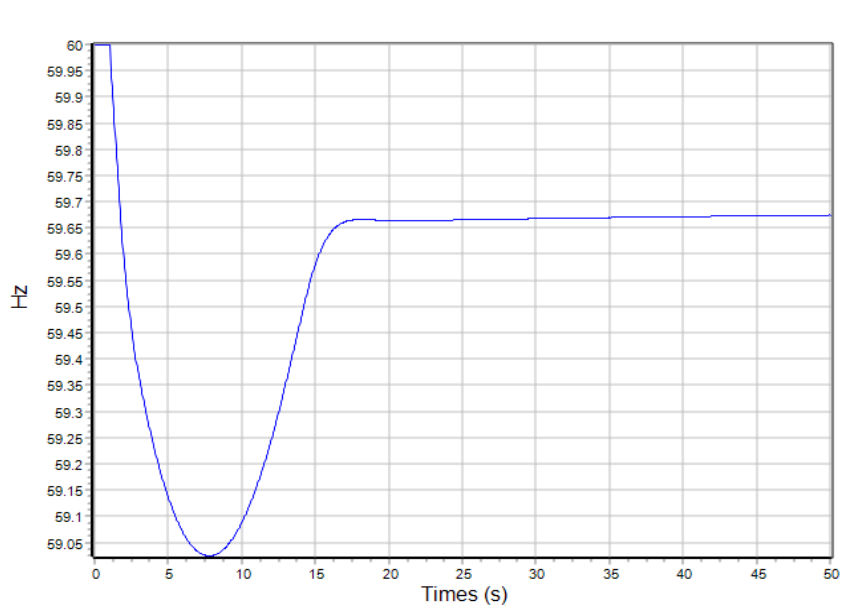

Fig. 6: The frequency of the system after the implementation of the primary and secondary control

$$
\Delta P_{L S \min }=\Delta P_{L}+\frac{\Delta f_{c p}}{f_{0}} \cdot \beta-\Delta P_{\text {Secondary control max }}
$$$$
\Delta P_{L}=P_{L}-\sum_{i=1}^{n-1} P_{G_{i}}=9.5394-8.31780=1.2216
$$$$
\beta=P_{L} . D+\sum_{i=1}^{n-1} \frac{P_{G i}}{R_{i}}=9.5394 x 0.02+187.4=187.59
$$$$
\Delta P_{L S \min }=1.2216+\frac{(-0.3)}{60} x 187.59-0.1072=0.1764 p u
$$

So, the minimum load shedding capacity of $\mathrm{P}_{\text {Load shedding min }}$ is $17.64 \mathrm{MW}$.

To test the effectiveness of the proposed method, this minimum load-shedding capacity is distributed for load nodes according to the importance factor of the load. The distribution table of load shedding capacity at the load bus is presented in Table 6 .

Comparing the proposed load shedding method with the load shedding method using the under frequency load shedding relay (UFLS) when performing with the same amount of shedding capacity is $17.64 \mathrm{MW}$. The result of frequency simulation and the economic losses associated with load shedding are presented in Figure 7 and Table 8.

Table 8. Comparing economic losses of load shedding based on AHP algorithm and UFLS

\begin{tabular}{|l|c|c|}
\hline Load shedding Methods & AHP & UFLS \\
\hline Load shedding (MW) & 17.64 & 17.64 \\
\hline $\begin{array}{l}\text { Economic damage } \\
\sum \mathrm{P}_{\mathrm{LSi}} \mathrm{C}_{\mathrm{mi}}\left(\mathrm{x} 10^{3}\right)(\$)\end{array}$ & 4391.5 & 4610.85 \\
\hline
\end{tabular}

It can be seen that the frequency values at steady state of both load shedding methods based on AHP and UFLS are restored to allowable value. The reason is due to load shedding with the same capacity. However, the frequency response quality of the UFLS method is not equal to the AHP method.

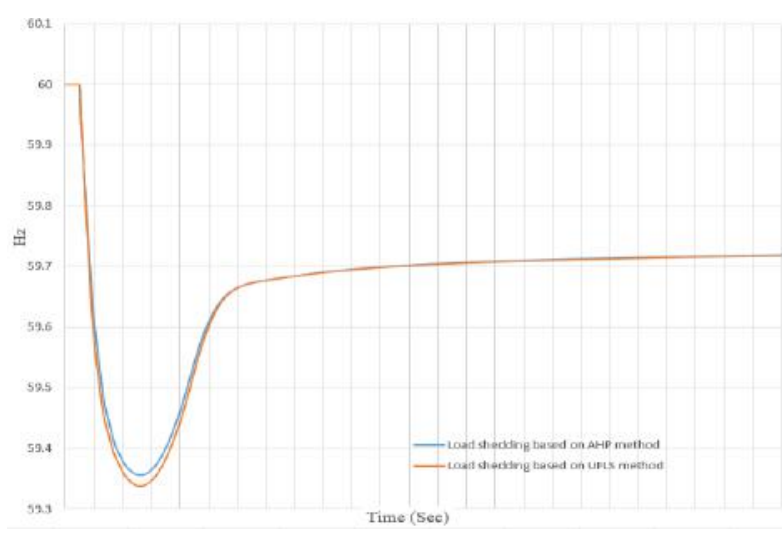

Fig. 7: The frequency of the system when applying the traditional and the proposed load shedding method

The reason is the UFLS method must wait for the frequency to drop below the set threshold to impact load shedding. Although they are shedding the same amount of power, the AHP method has about 5\% less damage value. The reason is that AHP method ranks the load and supports load shedding based on the importance factor. This has helped to reduce the value of the damage caused by load shedding. Thus, the method of calculating the minimum load shedding capacity has controlled frequency to restore back to the allowed value of $59.7 \mathrm{~Hz}$ and shows the effectiveness of the proposed method.

\section{CONCLUSION}

The calculation of the amount of load shedding capacity considering the primary frequency control and the secondary frequency control helps to minimize the amount of load shedding capacity. This helps the frequency to recover to the value within the permissible range.

A load shedding method considers to the primary and secondary control elements of the power plant to calculate the minimum amount of load shedding power and restore the frequency back to the allowable value.

The effectiveness of the proposed method has been demonstrated on the 9 generator 37-bus system under different test cases. The performance of this is found to be better than that of a conventional UFLS scheme. The test results show that the proposed method results in reduced the cost of customer service interruption. 


\section{ACKNOWLEDGEMENTS}

This work belongs to the project in 2020 funded by Ho Chi Minh City University of Technology and Education, Vietnam.

\section{REFERENCES}

[1] IEEE Standard. IEEE guide for the application of protective relays used for abnormal frequency load shedding and restoration. IEEE Std C37117-2007, p.41-43.

[2] ENTSOE operation handbook. Internet: https://www.entsoe.eu/publications/systemoperationsreports/operation-handbook, 26/09/2017.

[3] Barnabé Potel; Vincent Debusschere; Florent Cadoux; Leticia de Alvaro Garcia. Under-frequency load shedding schemes characteristics and performance criteria. IEEE Manchester PowerTech, 2017.

[4] Lukas Sigrist, Luis Rouco, Francisco Miguel, Echavarren. A review of the state of the art of UFLS schemes for isolated power systems. International Journal of Electrical Power \& Energy Systems, Vol. 99, pp.525-539, July 2018.

[5] IEEE guide for abnormal frequency protection for power generating plants, ANSI/IEEE Std C37106-1987.

[6] Yun Hwan Lee, Seung Chan Oh, Hwan Ik Lee, Sang Geon Park, Byong Jun Lee. Utilizing under voltage load shedding strategy to prevent delayed voltage recovery problem in korean power system. Journal of Electrical Engineering and Technology, Vol. 13, Issue 1, pp.60-67, 2018.

[7] V. V. Terzija. Adaptive Under Frequency Load Shedding Based on the Magnitude of the Disturbance Estimation, IEEE Transactions on Power Systems, Vol. 21, Issue 3, pp. 1260 - 1266, 2006.

[8] Asja Derviškadić, Yihui Zuo, Guglielmo Frigo, Mario Paolone. Under Frequency Load Shedding based on PMU Estimates of Frequency and ROCOF. IEEE PES Innovative Smart Grid Technologies Conference Europe (ISGTEurope), 2018.

[9] Junjie Tang, Junqi Liu, Ferdinanda Ponci, Antonello Monti. Adaptive load shedding based on combined frequency and voltage stability assessment using synchrophasor measurements. IEEE Transactions on Power Systems, Vol. 28, Issue 2, pp.2035-2047, May 2013.

[10] R. Hooshmand and M. Moazzami. Optimal design of adaptive under frequency load shedding using artificial neural networks in isolated power system. International Journal of Electrical Power \& Energy Systems, Vol. 42, Issue 1, pp. 220-228, 2012.

[11] J Sasikala, M Ramaswamy. Fuzzy based load shedding strategies for avoiding voltage collapse. Applied Soft Computing, Vol. 11, Issue 3, pp. 3179-3185,2011.

[12] Athila Quaresma Santos, Hamid Reza Shaker, Bo Nørregaard Jørgensen. A Holistic Fuzzy Measure for Load Priority in Under Frequency Load Shedding Schemes. International Symposium on Advanced Electrical and Communication Technologies (ISAECT), 2018.
[13] Paul Joshua, K., Mohanalin, J. \& Jaya Christa, S.T. Adaptive neuro-fuzzy inference system based underfrequency load shedding for Tamil Nadu. The Journal of Super computing, 2018.

[14] Marven E. Jabian, Ryohei Funaki, Junichi Murata. Load Shedding Optimization Considering Consumer Appliance Prioritization Using Genetic Algorithm for Real-time Application. IFAC-Papers OnLine, Vol. 51, Issue 28, pp.486-491, 2018.

[15] Abbas Ketabi, Masoud Hajiakbari Fini. Adaptive underfrequency load shedding using particle swarm optimization algorithm. Journal of Applied Research and Technology, Vol. 15, Issue 1, pp.54-60, February 2017.

[16] P. Kundur, Power System Stability and Control, McGrawHill, 1994.

[17] Sam Weckx, Reinhilde D'Hulst, Johan Driesen, "Primary and Secondary Frequency Support by a Multi-Agent Demand Control System", IEEE Transactions on Power Systems, Vol. 30, Issue: 3, pp. 1394 - 1404, 2015.

[18] A. J. Wood, et al., "Power Generation, Operation and Control," Third Edition, John Wiley \& Sons, Inc, pp. 473481, 2014.

[19] T.L. Saaty, The Analytic Hierarchy Process. McGraw-Hill, New York, 1980.

[20] J. Duncan Glover, Mulukutla S. Sarma, Thomas J. Overbye, "Power System Analysis and Design", Sixth Edition, Cengage Learning, pp. 718, 2017. 